\title{
Sistem Kontrol Temperatur Air pada Proses Pemanasan dan Pendinginan dengan Pompa sebagai Pengoptimal
}

\author{
Heru Sagito Palka*, Meqorry Yusfi \\ Jurusan Fisika, FMIPA, Universitas Andalas, Kampus Limau Manis Padang, 25163 \\ *sagitoheru@yahoo.co.id
}

\begin{abstract}
ABSTRAK
Perancangan sistem kontrol temperatur air pada proses pemanasan dan pendinginan menggunakan dua buah elemen Peltier dengan pompa sebagai pengoptimaltelah dilakukan.Keypad 3x4 digunakan untuk memberikan input nilai temperatur yang diinginkan lalu ditampilkan oleh LCD 2x16. Sensor LM35 digunakan sebagai pendeteksi perubahan nilai temperatur air. Mikrokontroler ATmega8535 akan memproses dan membandingkan nilai temperatur acuan dan nilai temperatur awal yang dideteksi oleh sensor. Apabila nilai temperatur acuan lebih besar dari nilai temperatur awal, maka sistem pemanas aktif. Apabila nilai temperatur acuan lebih kecil dari nilai temperatur awal,maka sistem pendingin aktif. Sistem kontrol on-off aktif untuk mengontrol temperatur sampai nilai yang sesuai. Sisi panas dan sisi dingin elemen Peltier dimanfaatkan sebagai pemanas dan pendingin. Proses pemindahan kalor terjadi secara konduksi melalui waterblock dan secara konveksi melalui pompa. Sistem kontrol dapat mempertahankan temperatur air yang diinginkan dengan kesalahan sebesar0,5 ${ }^{\circ} \mathrm{C}$. Kemampuan elemen Peltier menurun seiring bertambahnya massa air dan meningkat dengan bertambahnya jumlah elemen Peltier yang digunakan. Pada tegangan 12 V/3 A, satu elemen Peltier dapat menurunkan temperatur air bermassa $50 \mathrm{~g}$ hingga $19,3^{\circ} \mathrm{C}$.
\end{abstract}

Kata kunci : elemen Peltier, kontrol on-off, LM35

\section{ABSTRACT}

The design of control system of water temperature in the process of heating and cooling using two Peltier elements with a pump as optimizer has been done. Keypad $3 x 4$ was used to input the desired temperature and then displayed by the LCD 2x16. LM35 sensor was used as a detector of the water temperature changes. Microcontroller ATmega8535 will process and compare the temperature in the reference and the initial temperature detected by the sensor. If the temperature in the reference is greater than the value of the initial temperature, the heating system will be activated, and if the temperature in the reference is less than the value of the initial temperature, then the cooling system will be activated. The on-off control system actively organizes the temperature in the reference. The hot and cold side of Peltier element are used as heater and cooler. Process of heat transfer by conduction occurs through the waterblock and by convection occurs through the pump. The control system can maintain water temperature at reference value. The ability of Peltier element decreases with increasing of the mass of water and increased with increasing of number of Peltier elements. At voltage $12 \mathrm{~V} / 3 \mathrm{~A}$, aPeltier element can reduce the temperature of the water mass of $50 \mathrm{~g}$ down to $19.3^{\circ} \mathrm{C}$.

Keywords:Peltier element, on-off control,LM35

\section{PENDAHULUAN}

Dalam industri buah mangga terdapat perlakuan pascapanen untuk menghasilkan produk yang berkualitas seperti proses pencucian dan proses penyimpanan. Menurut Ilmi (2015) perlakuan pascapanen yang efektif adalah dengan pencucian pada temperatur air $(52-54)^{\circ} \mathrm{C}$ dan penyimpanan pada temperatur air $(15,1-17,1)^{\circ} \mathrm{C}$. Berdasarkan hal tersebut, perlu adanya suatu alat yang dapat mengontrol temperatur air pada proses pemanasan dan pendinginan.

Elemen Peltier dapat digunakan sebagai media pendingin dan pemanas air yang dapat memompa panas dari satu sisi ke sisi lainnya sesuai arah arus yang diberikan. Umboh (2012) menggunakan elemen Peltier untuk perancangan alat pendingin portable, dimana air bermassa $100 \mathrm{~g}$ dapat didinginkan sampai temperatur $22^{\circ} \mathrm{C}$.Kuscu dan Kahveci (2012), memperoleh hasil bahwa waktu pendinginan air mengunakan elemen Peltier akan semakin efisien jika perbandingan antara luas permukaan dan ketinggian gelas yang kecil. Pada penelitian Putra (2014), disebutkan bahwa elemen Peltier bisa digunakan sebagai pendingin ruang didalam box berukuran $(50 \times 15 \times 25) \mathrm{cm}$. Gandi (2015) memperoleh hasil bahwa elemen Peltier dapat menurunkan temperatur air bermassa $50 \mathrm{~g}$ hingga $5,7{ }^{\circ} \mathrm{C}$. Dalam metode pendinginan atau pemanasan, tinggi air dan elemen Peltier harus dibatasi agar tidak bersentuhan dengan elemen Peltier, sehingga perlu metode dengan menggunakan pompa agar elemen Peltier tidak 
bersentuhan langsung dengan air. Penelitian ini akan merancang sebuah sistem kontrol temperatur air pada proses pemanasan dan pendinginan dengan menggunakan elemen Peltier dan pompa sebagai pengoptimal. LM35 digunakan sebagai sensor temperatur dan sistem minimum mikrokontroler Atmega8535 sebagai pemroses sistem rangkaian.

\section{METODE}

\subsection{Perancangan diagram blok}

Gambar 1 adalah diagram blok sistem pengontrolan temperatur air secara keseluruhan. Prinsip kerja dari pengontrolan temperatur yaitu diawali oleh masukan pada keypad. Sebelum masukan itu dilaksanakan, mikrokontroler akan memproses sinyal masukan. Apakah sinyal masukan itu kecil dari nilai temperatur maksimum dan besar dari nilai temperatur minimum yang dapat dicapai oleh elemen Peltier. Jika syarat itu terpenuhi, maka mikrokontroler akan memproses apakah sinyal masukan itu kecil dari nilai temperatur yang dideteksi oleh LM35 atau besar dari nilai temperatur yang dideteksi oleh LM35. Jika sinyal masukan kecil dari nilai temperatur yang dideteksi oleh LM35 maka mikrokontroler akan mengaktifkan salah satu relai sehingga elemen Peltier hidup untuk mendinginkan air. Jika sinyal masukan besar dari temperatur yang dideteksi oleh LM35, maka mikrokontroler akan mengaktifkan relai lain sehingga elemen Peltier hidup untuk memanaskan air.Selama proses pendinginan atau pemanasan pompa akan terus mengalirkan air dari box ke elemen peltier untuk dipanaskan atau didinginkan lalu dialirkan lagi ke box. LM35 akan terus mendeteksi temperatur dan nilainya ditampilkan di LCD. Pada saat LM35 mendeteksi nilai temperatur yang sama dengan nilai temperatur yang dimasukkan dari keypad, maka mikrokontroler akan menon-aktifkan relai. Pada saat itu juga elemen Peltier akan berhenti mendinginkan atau memanaskan sampai ada instruksi lagi dan begitu seterusnya.

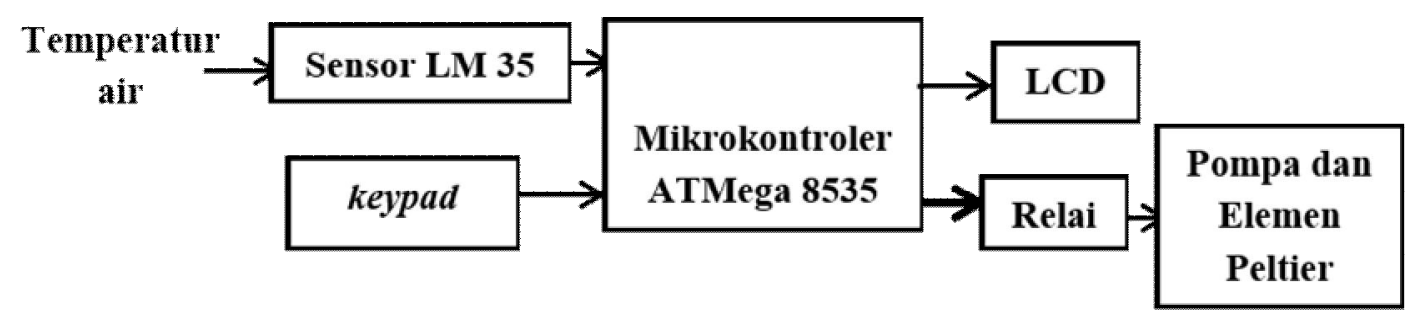

Gambar 1 Diagram blok kontrol temperatur

\subsection{Perancangan perangkat lunak sistem}

Penjelasan langkah kerja sistem kontrol temperatur air adalah sebagai berikut :

1. Pada awal program, nilai temperatur awal air langsung dideteksi oleh LM35 pada saat alat dihidupkan

2. Nilai temperatur yang diinginkan diinput melalui keypad.

3. Keluaran dari keypad akan diproses oleh mikrokontroler. Apabila input nilai temperatur lebih kecil dari nilai temperatur awal, maka relai 1 akan aktif sehingga elemen Peltier mulai melakukan proses pendinginan. jika tidak, maka relai 2 akan aktif sehingga elemen Peltier mulai melakukan proses pemanasan.

4. Ketika proses pendinginan atau pemanasan berlangsung, nilai temperatur ditampilkan oleh LCD.

5. Apabila nilai temperatur sudah sama dengan nilaiinput yang diinginkan, maka proses pendinginan atau pemanasan berhenti. Jika belum, elemen Peltier terus melakukan proses pendinginan atau pemanasan sampai memenuhi syarat. 
Diagram alir sistem kontrol temperatur air dapat dilihat pada Gambar 2.

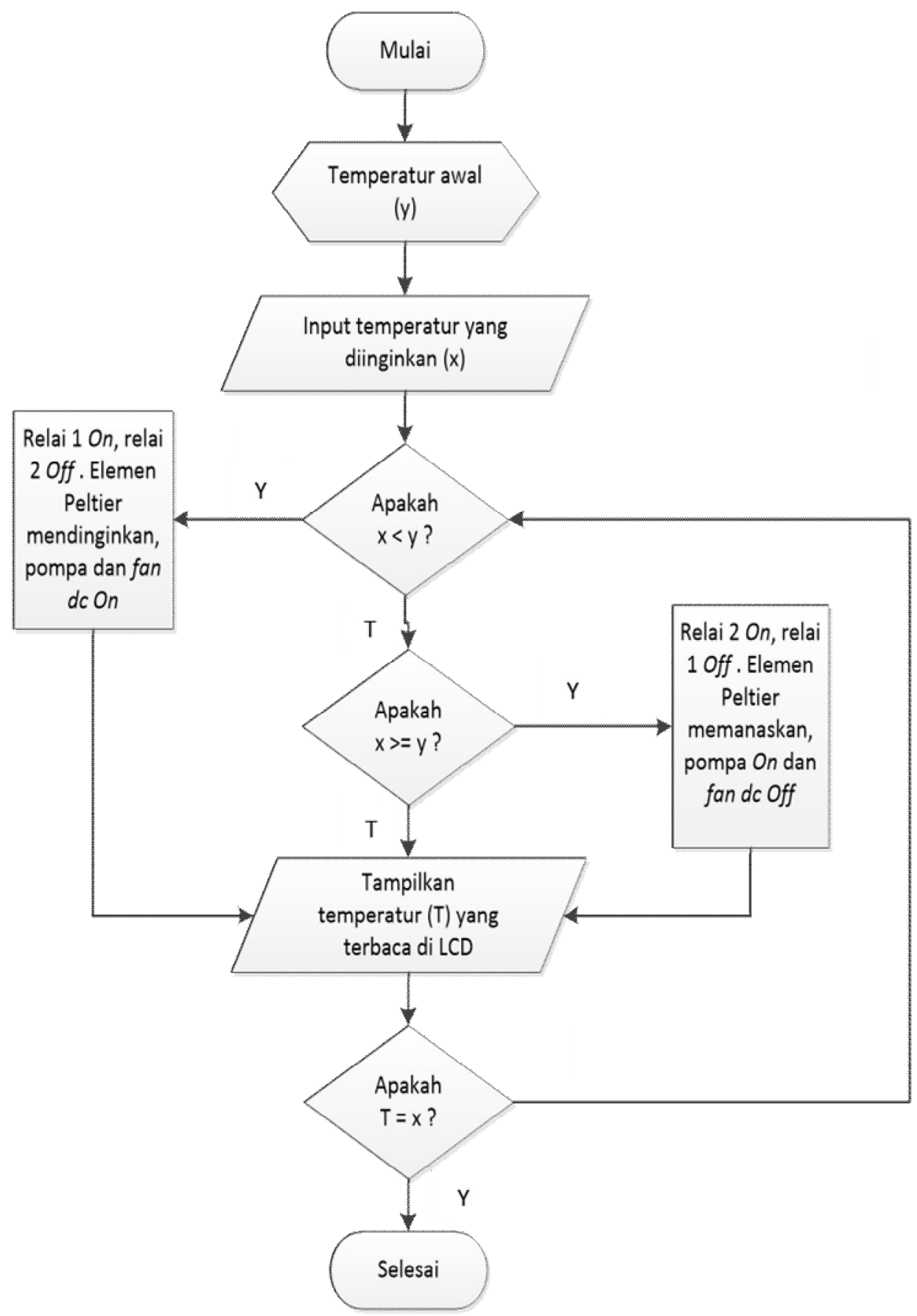

Gambar 2 Diagram alir perangkat lunak sistem kontrol temperatur

\subsection{Perancangan alat keseluruhan}

Pada metode ini, elemen Peltier, pompa, dan sistem rangkaian diletakkan secara terpisah. Proses pengontrolan dawali dengan memasukkan nilai temperatur melalui keypad. Sensor LM35 mendeteksi nilai temperatur awal sebagai sinyal acuan. Mikrokontroler akan memproses dan membandingkan sinyal masukan dengan sinyal acuan. Apabila terdapat sinyal error maka mikrokontroler akan mengaktifkan relai. Jika sinyal input lebih kecil dari sinyal acuan maka mikrokontroler akan mengaktifkan relai untuk proses pendinginan air, jika sinyal input lebih besar dari sinyal acuan maka mikrokontroler akanmengaktifkanrelai untuk proses pemanasan air sampai nilai temperatur air sama dengan nilai temperatur acuan. Rancangan alat keseluruhan dapat dilihat pada Gambar 3. 


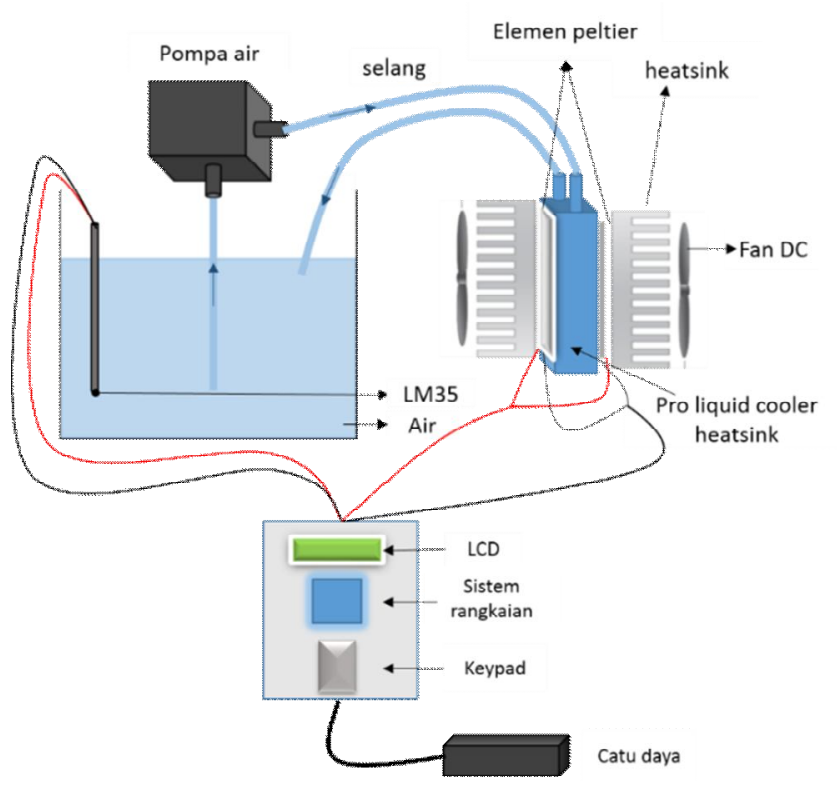

Gambar 3 Rancangan alat keseluruhan

\section{HASIL DAN DISKUSI}

\subsection{Pengujian proses pendinginan oleh 1 elemen Peltier TEC-12706 dengan bantuan pompa air}

Gambar 4 merupakan grafik hubungan nilai temperatur terhadap waktu pada proses pendinginan dengan 1 elemen Peltier. Berdasarkan Gambar 4, dapat dilihat bahwasemakin tinggi massa air maka kemampuan pendinginan akan semakin rendah. Air dengan massa $50 \mathrm{~g}$ memiliki temperatur akhir yang lebih rendah dibanding beban lain, yaitu sebesar 19,3 ${ }^{\circ} \mathrm{C}$.Kemampuan pendinginan secara keseluruhan tidak jauh berbeda, namun pada waktu 15 menit pertama kecepatan pendingin lebih cepat daripada menit selanjutnya. Dapat disimpulkan bahwa kemampuan pendingin pada semua variasi massa hampir sama.

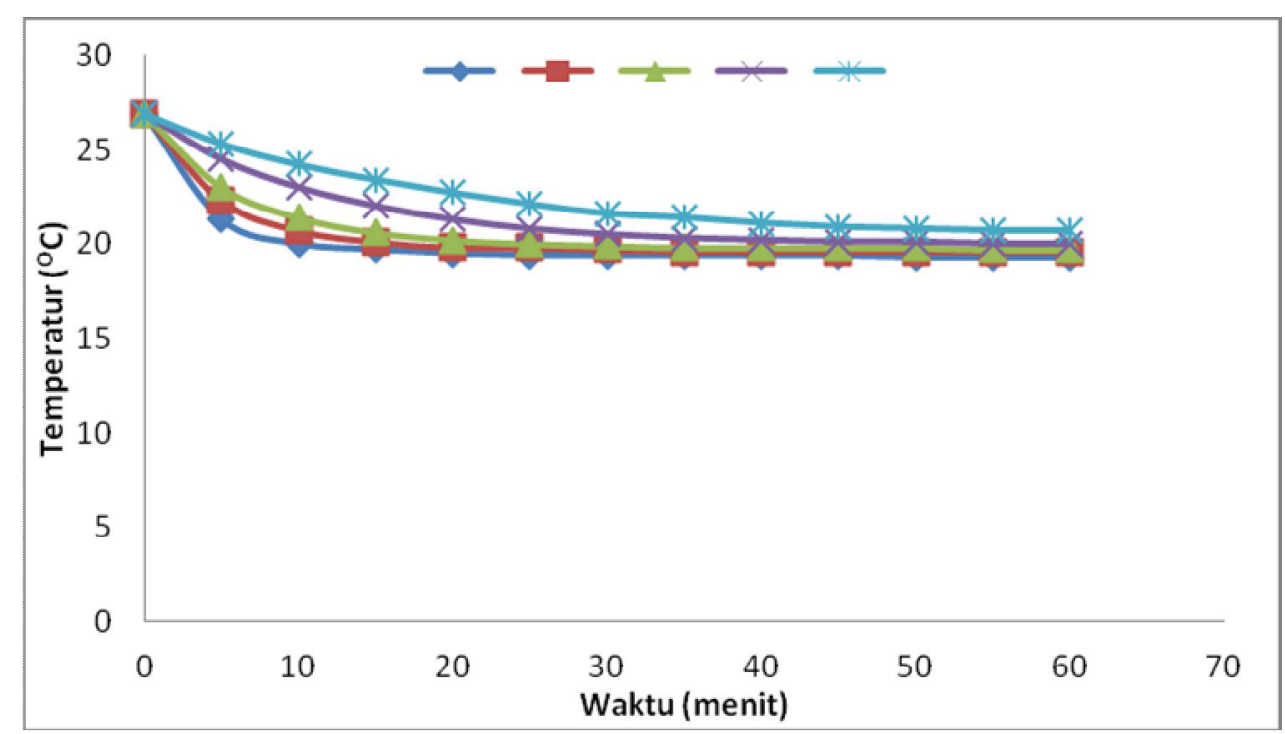

Gambar 4 Grafik hubungan temperatur terhadap waktu pada proses pendinginan oleh 1 elemen Peltier pada tegangan 12V/3A untuk beberapa massa air

Berdasarkan data yang diperoleh dari hasil proses pendinginan dengan 1 elemen Peltier, temperatur minimum yang dapat dicapai oleh elemen Peltier masih tinggi jika dibandingkan dengan penelitian sebelumnya yaitu Gandi (2015) yang memperoleh hasil bahwa elemen Peltier dapat menurunkan temperatur air bermassa 50 gram hingga $5,7^{\circ} \mathrm{C}$. Hal ini dikarenakan arus yang diterima oleh elemen Peltier tidak optimal karena elemen Peltier dihubung secara paralel 
dengan fan $D C$ dan pompa air. Proses pembuangan kalor pada sisi panas elemen Peltier oleh fan $d c$ melalui heatsink yang belum optimal karena ukuran heatsink dan daya dari fan kecil juga membuat proses pendinginan belum maksimal.

\subsection{Pengujian alat keseluruhan dengan 2 elemen Peltier}

\subsubsection{Kontrol temperatur air pada proses pendinginan}

Grafik pada Gambar 5 memperlihatkan bahwa alat melalukan proses pendinginan air dimulai pada temperatur awal sebesar $27,3{ }^{\circ} \mathrm{C}$. Nilai temperatur yang diinginkan adalah $17{ }^{\circ} \mathrm{C}$. Nilai temperatur yang diinginkan dapat dicapai dalam waktu 4491 detik. Sistem kontrol mematikan proses pendinginan saat temperatur air sedikit lebih kecil dari nilai temperatur acuan yaitu sebesar $16,6^{\circ} \mathrm{C}$. Setelah itu temperatur air naik karena pengaruh lingkungan sampai 17,1 ${ }^{\circ} \mathrm{C}$. Saat itu sistem kontrol kembali mengaktifkan sistem pendinginan sampai nilai temperatur terbaca $16,6{ }^{\circ} \mathrm{C}$ dan begitu seterusnya.Jadi, sistem kontrol dapat mengontrol temperatur air sampai pada nilai temperatur acuan, namun terdapat perbedaan sebesar $0,5{ }^{\circ} \mathrm{C}$ antara nilai temperatur air yang diinginkan dengan nilai temperatur air saat sistem dimatikan. Hal ini dikarenakan nilai sensitivitas sensor LM35 adalah sebesar 0,5 , sehingga setiap perubahan tegangan $10 \mathrm{mV}$ nilai temperatur berubah sebesar $0,5^{\circ} \mathrm{C}$.

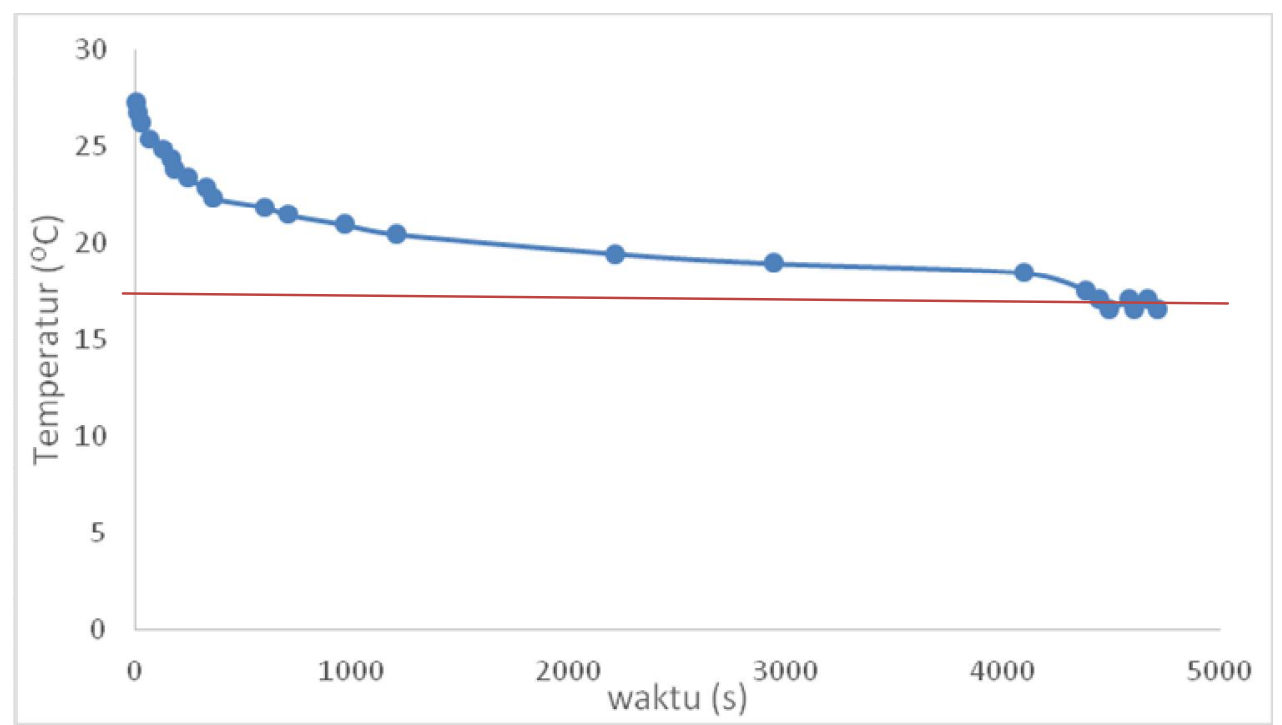

Gambar 5 Grafik hubungan temperatur terhadap waktu pada sistem kontrol temperatur air pada proses pendinginan

\subsubsection{Kontrol temperatur air pada proses pemanasan}

Dari Gambar 6dapat dilihat bahwa alat melakukan proses pemanasan air dimulai pada temperatur awal sebesar $26,8^{\circ} \mathrm{C}$. Nilai temperatur yang diinginkan adalah sebesar $49{ }^{\circ} \mathrm{C}$. Nilai temperatur yang diinginkan dapat dicapai dalam waktu 2790 detik. Sistem kontrol on-off dapat mempertahankan temperatur air pada proses pemanasan air. Sistem kontrol mematikan sistem pemanasan saat temperatur $49,3{ }^{\circ} \mathrm{C}$. Setelah itu besar temperatur air turun karena pengaruh lingkungan. Pada saat temperatur air $48,8{ }^{\circ} \mathrm{C}$ sistem kontrol menghidupkan kembali sistem pemanasan sampai nilai $49,3{ }^{\circ} \mathrm{C}$ dan begitu seterusnya. Pada proses pemanasan ini juga terdapat perbedaan sebesar $0,5^{\circ} \mathrm{C}$ antara nilai temperatur air yang diinginkan dengan nilai temperatur air saat sistem dimatikan. 


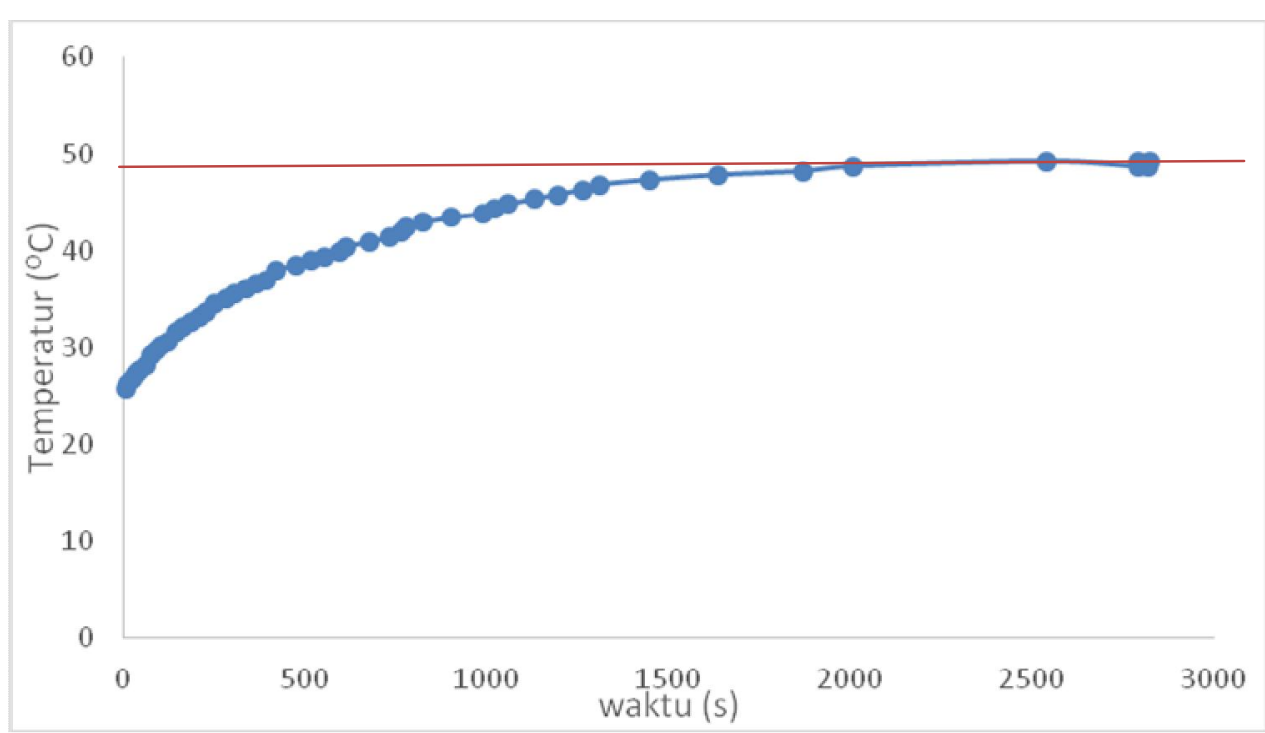

Gambar 6 Grafik hubungan temperatur terhadap waktu pada sistem kontrol temperatur air pada proses pemanasan

\section{KESIMPULAN}

Kemampuan pendingin dan pemanas berkurang seiring pertambahan massa air. Pada tegangan $12 \mathrm{~V} / 3 \mathrm{~A}$, satu elemen Peltier dapat menurunkan temperatur air bermassa $50 \mathrm{~g}$ hingga $19,3^{\circ} \mathrm{C}$. Sistem kontrol temperatur air dengan 2 elemen Peltier dapat mengontrol temperatur air pada proses pendinginan dan pemanasan, namun ada sedikit perbedaan sebesar $0,5^{\circ} \mathrm{C}$ antara nilai temperatur yang diinginkan dengan nilai temperatur air saat sistem dimatikan. Alat ini sudah mampu melakukan proses pemanasan dan pendinginan untuk mencapai temperatur yang diperlukan pada perlakuan pascapanen buah mangga.

\section{DAFTAR PUSTAKA}

Gandi, F.,"Perancangan Sistem Kontrol Temperatur Pada Proses Pendingin Air Menggunakan Elemen Peltier Berbasis Mikrokontroler ATMEGA 8535", Skripsi S1, Universitas Andalas, 2012.

Ilmi, NK., "Perlakuan Air Panas dan Pengaturan Suhu Simpan untuk Mempertahankan Kualitas Buah Mangga (Mangifera indica L.) cv. Gedong”, Skripsi S1, Institut Pertanian Bogor, 2015.

Kuscu, H., dan Kahveci, K., "Cooling Time of Water in a Glass on a Thermoelectric Cooler", Vol.6, No.1, Bulgaria, 2012.

Putra, W.,"Perancangan dan Implementasi Kontrol Temperatur pada Proses Pendinginan Menggunakan Termoelektrik", Skripsi S1,UNAND, 2014.

Umboh, R., "Perancangan Alat Pendinginan Portable Menggunakan Elemen Peltier", Skripsi S1, UNSRAT, 2012. 